\title{
2006-897: POWER PLANT PROPOSAL AND FEASIBILITY: A STUDENT PROJECT FOR A THERMODYNAMICS COURSE
}

\section{Carl Fayerweather, University of Toledo}

Carl is a graduate student in Mechanical Engineering.

\section{Sorin Cioc, University of Toledo}

Dr. Cioc is a visiting professor of Mechancial Engineering.

\section{Douglas Oliver, University of Toledo}

Dr. Oliver is undergraduate director of the mechanical engineering program at the University of Toledo. He is also an attorney. 


\title{
Power Plant Proposal and Feasibility: A Student Project for a Thermodynamics Course.
}

\begin{abstract}
This paper introduces a student project for a second-semester thermodynamics class. The project involves competing student teams. Team members select a method of power generation (wind, coal, nuclear, etc.) for a specific geographic location. Then the teams research the feasibility of situating a new power plant in that location using the selected method of power generation. Finally, student teams debate the positive and negative aspects of the selected power generation methods. This project is designed to address several ABET criteria.
\end{abstract}

\section{Introduction}

The objective of the following paper was to satisfy two relatively new and so far rarely addressed criteria of ABET, namely ABET (3)(c) and ABET (3)(j). Therefore, for the fall semester in the Thermodynamics II class, the students were assigned a project with the following premise:

Propose a specific type of power source to add to the power grid in a given location and defend your choice against another power source.

This is relevant to the class because the coursework in Thermodynamics II could be considered the groundwork for power generation. The project did not focus on how a certain power source worked, but rather why that certain power plant would be an effective power source for the specific geographical region. This was important because it gave the students practice in an area of engineering that ABET requires, but is many times overlooked in engineering. As a result of the oral presentations, this project also aids in the practice of communication [ABET criteria $(3)(\mathrm{g})]$.

The objective of the project was to have the students examine the benefits and repercussions of building a new power plant. We had the students examine questions like the following:

How much will this project cost? How long will the power plant last? How reliable is it? How will the environment be affected? What will this do to the local economy? How many jobs will be created? How much will the electricity cost? Will the government subsidize this plant?

Because these questions are related to the economy, the environment and political and societal issues this portion of the project satisfies ABET criteria (3)(c) which reads:

Engineering programs must demonstrate that their students attain an ability to design a system, component, or process to meet desired needs within realistic constraints such as economic, environmental, social, political, ethical, health and safety, and manufacturability. (www.ABET.org) 
This project also satisfies the ABET criteria (3)(j) which reads:

Engineering programs must demonstrate that their students attain knowledge of contemporary issues. (www.ABET.org)

This was accomplished by having the students examine advancements in technology that have improved the efficiency of different power plants and by having them investigate newer and possibly less known forms of power generation. Also they were to research issues like terrorism, price fluctuations and cost of construction.

Finally, this project gave the students practice with communication skills. After they researched their topic, they had to give a presentation to convey what they had found. Communication skills are difficult to practice and the more opportunities the students have to present on engineering topics, the better. This area of the project satisfies the ABET criteria (3)(g) which reads:

\section{Engineering programs must demonstrate that their students attain an ability to communicate effectively. (www.ABET.org)}

The project was assigned to a thermodynamics class that is normally taken by secondsemester juniors in mechanical engineering. No special skills, such as debating, cost analysis, or project management were taught in this class. However, prior to taking this course, students should have completed two courses in English and a course in Engineering Economics. As such, we felt it was a reasonable assumption that the students had the requisite background to complete this task with little supervision.

\section{The Project}

The format of the project was the result of improvements made over a period of multiple semesters. Considering the size of the class (48 people), it was first decided that the students would work in groups of eight consisting of two teams each. The students were asked to choose three aspects of the project: pick which students they wanted to work with; decide what power source they wanted to advocate; and where they wanted to construct this new power source. Both teams needed to consider one common location for their project. They also needed to ensure that their choices were logical.

For example, in the Nevada region, solar power and hydroelectric power are two obvious choices due to the rivers in the region, perfect for new dams and vast reaches of desert that are ideal for solar panels. If a group of students could not agree on a power source or location, the choice was made for them. This happened with only two teams and worked out well because it allowed us to round out the variety of power sources and make sure that no one power source was covered more than twice. After the initial choices were made, the students set out to begin research.

The objective for each team was to convince their classmates why their design was better than the others' team design. As stated before, they would not be only looking at how a certain power source works, but rather what kinds of impacts it has on society and nature and why their power plant is a better choice than their opponents'. Furthermore, if the assigned power source had certain stigmas attached to it, the groups would attempt to find support for why this stigma was wrong. However, if this stigma was right, they 
should explain what steps are being taken to improve this shortcoming. The information gained was then organized into a formal report to be submitted as a part of the total grade. This paper was to address economic, environmental, contemporary and social issues, becoming the foundation of their presentation.

The fact that they were asked to present reasons why their power plant was better suited for the area than their opponents' required the students to research both types of power generation chosen by their group. The debate was conceived in order to make sure the teams knew a great deal about their topic, were able to defend its shortcomings and know enough about the other team's topic to show that the opponents' power source would not be as successful in that region as their own.

The presentations were limited to 8 minutes of presenting and 2 minutes of rebuttal. This gave the students practice in time management. With this limited time, it was a challenge to present both reasons to support their power source, and to outline why their opponents design was less desirable. Another reason for the limited time was to make sure the projects, as whole, took a maximum of three one-hour classes.

After both teams presented, they were given 2 minutes to rebut. This may seem like too little time, but the teams knew the rebuttal was coming and therefore were given ample time to predict what the opposing team would criticize and therefore be able to defend. Although teams would no doubt attack multiple aspects of the others power source, they needed to decide which of those aspects to refute based on its importance.

In order to increase the students' interest, part of their grade was based on how convincing they appeared to the rest of the class. This part of the grade was not so high that it could cripple a group's grade if they were not persuasive enough, or if the opposing group made an outstanding presentation. This part of the grade was given by dividing a total of 20 percentage points between the two teams, proportionally to the number of votes each team received from a class ballot organized after each debate.

The presentation and debate format, while relatively unusual for engineering classes, was conceived to be an effective way to reinforce the ideas embedded in ABET criteria (3)(c) and $(3)(j)$. The reason for this was that, in practice, engineers often must present an idea, design project, or proposal to a mixed audience formed by technical and non-technical people, also that the choices they make are many times influenced by external, nontechnical criteria.

\section{Picking the Location and Power Source}

The very first decision the students had to make was picking a power plant that made sense for the selected geographic region. They needed to look at different regions and decide what type of power plants would work in each area depending on natural resources, population density, etc.

An example would be for them to determine if there was a close enough coal mine to justify a coal-fired plant, otherwise the transportation fees might make the coal-fired plant unfeasible. Another example could be that putting a large scale nuclear power plant in Montana would be excessive because of its low population, there might not be a demand for the large amount of power that a nuclear plant offers. The students had no 
problem recognizing this and instead made choices like the following: Geothermal power for the Cascade Mountains region where volcanic activity is high, biomass power for the Midwest where farm waste is abundant, and oil-fired power for oil rich Texas. This portion of the project satisfies ABET criteria (3)(c) because it has the students make decisions with realistic environmental and economic constraints.

\section{The Price of Electricity}

The next section of the project dealt with the cost per kilowatt-hour associated with individual power plants. A problem arose when the teams had different values for the cost per kilowatt hour than their opposition. Each team quoted costs that supported their power source. However the opposing team's quote costs were quite different. In every presentation both teams would agree that one power source was more expensive than the other, but the gap in price was often very different between the two teams. This was presumably done as a way to make one power source look better or worse than it actually was. Also, this showed the students that not all references are equal. It illustrated that even a seemingly simple concept like price per kilowatt hour, can be a source of confusion. This part of the presentation should not have been confusing as a result of inconsistent numbers. Students suggested that this confusion could be reduced by meeting and agreeing on "the facts" prior to the presentations, to leave more room for debate on the opinions. This section satisfies ABET criteria (3)(c) by having the students examine economic issues.

\section{How Power Plants Affect the Community}

How the plants would affect society was another factor considered. The students examined how many jobs the plants created and used this to support their own plant as being good for the economy if it created a significant work force. More creatively, one of the groups acknowledged that the creation of a dam will result in a large lake being formed. This will translate into new recreation and tourism opportunities. It was also found that many of the renewable power sources tend to require small amounts of people to keep the plant running. The opposite was true for the fossil fuel and nuclear power facilities.

These types of questions need to be addressed when considering building a new plant because people want to have cheap electricity, but they also want to feel safe and gain new jobs. Although no single power source can meet all needs, this project allowed the students construct arguments that acknowledged the faults but show that their power source was still the best choice for their region, satisfying the ABET criteria (3)(c).

\section{Environmental Effects}

The students found that every type of power station has some effect on nature or wildlife or both. The creation of dams, for instance, hinders the migration of fish to spawning grounds. The hydroelectric teams however informed us that dams now build fish ladders. It was also addressed that building a dam required massive flooding and thus the extermination of all the plants that reside in the manmade flood zone.

Another example would be the effects on the environment brought on by coal plants. Although there is still significant emission problems associated with coal plants, those 
conditions have improved drastically and keep getting better. However, there still is the problem with strip mining.

Solar and wind power, do not cause any direct pollution (save the pollution emitted when they were made). However, they do take up large amounts of land in order to be effective. And even though they can be put on land that is away from communities, they still will have effects on the wildlife. For instance, wind farms cause bird deaths. They also cause noise pollution.

It was also pointed out that solar panels can be very hazardous when their lifetime is up. When they are discarded, their components, such as arsenic, can erode and leak into the environment. As stated before, every type of plant has negative impacts on the environment. This part was especially useful for the students because it let them know that even the "green" power sources may not be as clean as would appear on first sight. This portion of the project satisfied ABET criteria (3)(c) in that they learned how different power stations affect nature and wildlife.

\section{Reliability of Power Sources}

The proponents of the different power sources seemed to be forthright about the longevity and shortcomings of their representative power plants. As such, the students took it upon themselves to inform the class of their plant's weaknesses and measures taken to account for these problems. For instance, the groups that presented on solar power farms readily admitted that solar panels are subjected to abrasion and dulling of surfaces which limit their lifetime. They also did not try to hide the fact that the panels do not produce as much power if the sky is overcast. They did, on the other hand, give solutions to this problem, such as different battery components to store unused energy. Another example would be when the team that advocated on nuclear power discussed the possibilities of meltdown. They did mention the Chernobyl disaster and the corrosion problems at Davis Besse. However, they showed several precautions that are taken to prevent such occurrences in the future. There was a disparity in the lifetimes of the different plants according to the findings of the teams, but it was not so large to cause any confusion.

\section{Power Plants and National Security}

The next section dealt with national security impacts associated with a given power plant. In today's political climate, knowing what kind of national security risks went along with different plants is another important decision factor concerning the feasibility of a new electric power source. What the students found was that the plants that did not offer a large amount of electricity were less at risk for terrorist action. This is partially because many of the small output plants have a large footprint, therefore it would be difficult to significantly disrupt the power grid. An example of this would be wind or solar farms. Both of these sources require a great deal of land, it is hard to destroy enough of the plants components to see a significant power loss. Also, it was found that the large output plants contain components that if attacked could result in a total loss of the power plant. Some of the groups may have taken the effect a little too far, like suggesting a full nuclear explosion. They at least hit the mark that taking out high output plants, which tend to have small footprints, could severely harm the power grid. Since terrorism and 
national security are important contemporary issues, this gave the students knowledge relating engineering and contemporary issues as per ABET criteria (3)(j).

\section{Cost of Constructing a New Plant}

Another item to consider was the cost of the new plant. This was an important step because it is necessary to find out if and when the plant will pay for itself. This step was determined in large part by the initial construction cost, predicted future cost of maintenance and power output. There was a little vagueness in this area, which one team recognized, and then all subsequent teams followed suit. One group would propose a certain power output, and would compare it to the other power plant that had the same construction cost, but not the same power output. This seemed unfair because when comparing say solar and coal, $x$-dollars only gives you a $y$-MW solar farm where it can give you a much more powerful coal-firing plant.

After watching the presentations, a pattern arose: If the initial construction cost was high, the continued maintenance was usually low. So just because it cost more to get the plant started, does not mean that should be the only cost acknowledged. For instance, the students showed that solar panels are initially expensive. But once they are constructed, very little maintenance is required to keep them working. One group recognized this and compared two plants with the same output, and worked out their figures from there. This was a significant improvement because the audience got a better feel of what different plants would cost to supply the same electricity. In future presentations, this improvement should be stressed upon the groups to allow the audience to make a more informed decision on which plant is better.

\section{Student Feedback}

At the end of the project the class received a feedback survey with ten questions. This survey is attached with average response. According to the class average, there were no overall negative feelings toward the project. In two of the areas, question 1 and 2, the students felt strongly positive toward the project. This is reassuring because these two questions dealt with the two main ABET criteria meant to impress on to the students, $\operatorname{ABET}(3)(c)$ and (3)(j).

The students were also encouraged to write comments on the project. Most of the comments dealt with the short amount of time given for the presentation and debate. However, since the amount of time was equal for every team, they did not see it as unfair. The presentations needed to take no more than one week of class. Since we were dealing with a class of 48 students, the duration of the presentations had to be strictly limited.

Also included is a graphical presentation of the results for four of the questions. The graphs are in the format of student rating vs. number of responses with that rating. The first two graphs show the ratings that the students gave with regards to the two ABET criteria that we were most focused on. The first question and first graph revolved around ABET criteria (3)(j) which received an average score of 4 , where most of the responses were "agree" and the second highest rating was "strongly agree." The second question and second graph was concerned with ABET criteria (3)(c) which received an average score of 4.4 where there were only 3 less votes for "strongly agree" than for "agree." 
These two examples show that the students felt that these two ABET criteria were successfully addressed.

The forth question, (the third graph), is included because of its average value of 2.5, where most of the votes were "disagree." This question asked whether or not the students felt this project took too long. This is important to point out because most of the results for the other questions were between 3 and 4, where we were looking for a high rating or as close too "strongly agree" as possible. However, we wanted to see a low number for question four, which is what we found. This shows that the students were honestly answering the questions and not just filling out the sheet without paying attention.

Finally, included in the final graph is question number nine, which got a value of 3.9. This question asked whether or not this project should be included in future classes. Most of the students gave a rating of "agree." The other part of the class was, for the most part, split between "neutral" and "strongly agree." This shows that approximately $75 \%$ of the class agrees that this project should continue in the future.

The remaining questions, all got at least an average rating of 3.7 which is close to the average of agree. However, the majority of the votes on each of the questions were for "agree", and for all but one question, over half the class voted "agree."

\section{Planned Changes for Next Semester}

As mentioned above, we will add a requirement that the opposing teams meet prior to the presentations to compare prices and other quantitative data. By doing this, we hope much of the ambiguity regarding costs will be eliminated.

Students expressed concern that the time allocated for the debate was too short. We agreed that it would be nice to give the students more time to present. However, this project already required one week of lecture and allotting anymore time to the debates was not justified. Probably, with smaller classes this could be done.

\section{Conclusion}

Based on what was observed in the presentations and what the students reported in the feedback form, we believe that this project was a very good experience for the class. This project satisfies the ABET criteria (3)(c) and (3)(j). In our opinion, the students learned a great deal about researching the benefits and consequences of building a new power plant in a particular region.

\section{References}

Download Forms and Criteria. http://www.abet.org/forms.shtml. Last Modified: January, 17 2005. ABET. 


\section{Appendix A: Student Feedback Form}

The following statements were given to the students after the presentations were completed. On every question they were to rate their opinions with the following scale:

\begin{tabular}{|l|l|l|l|l|}
\hline 1: Strongly Disagree & 2: Disagree & 3: Neutral & 4: Agree & 5: Strongly Agree \\
\hline
\end{tabular}

We tabulated all the results and reported the average value for each statement. Also included (on the page following statements) are graphs for the statements we found to be most significant, represented as columns that reflect the number of students that shared that particular response. Here are the statements the students were asked to respond to:

1. Compared to a standard approach, this project demonstrated better that thermodynamics affects contemporary issues. (Average $=4$ )

2. This projected demonstrated how economic, environmental, and societal concerns must be included in the design process. (Average $=4.4$ )

3. This project helped me communicate more effectively. (Average $=3.4$ )

4. This project took too much time. (Average $=2.5$ )

5. I enjoyed this project more than a standard lecture/homework/quiz approach. (Average $=3.7$ )

6. I learned a lot of new information watching my colleagues presenting their projects. (Average $=3.8$ )

7. The debate made the project more effective than a traditional student presentation. (Average $=3.8$ )

8. I worked harder, knowing that the students would vote on my team's effectiveness. (Average $=3.7$ )

9. This project should be adopted as a permanent component of future thermodynamics classes. (Average $=3.9$ )

10. I consider this design project to be an excellent experience. (Average $=3.7$ ) 


\section{Appendix B: Selected Statement Responses Graphically Represented}
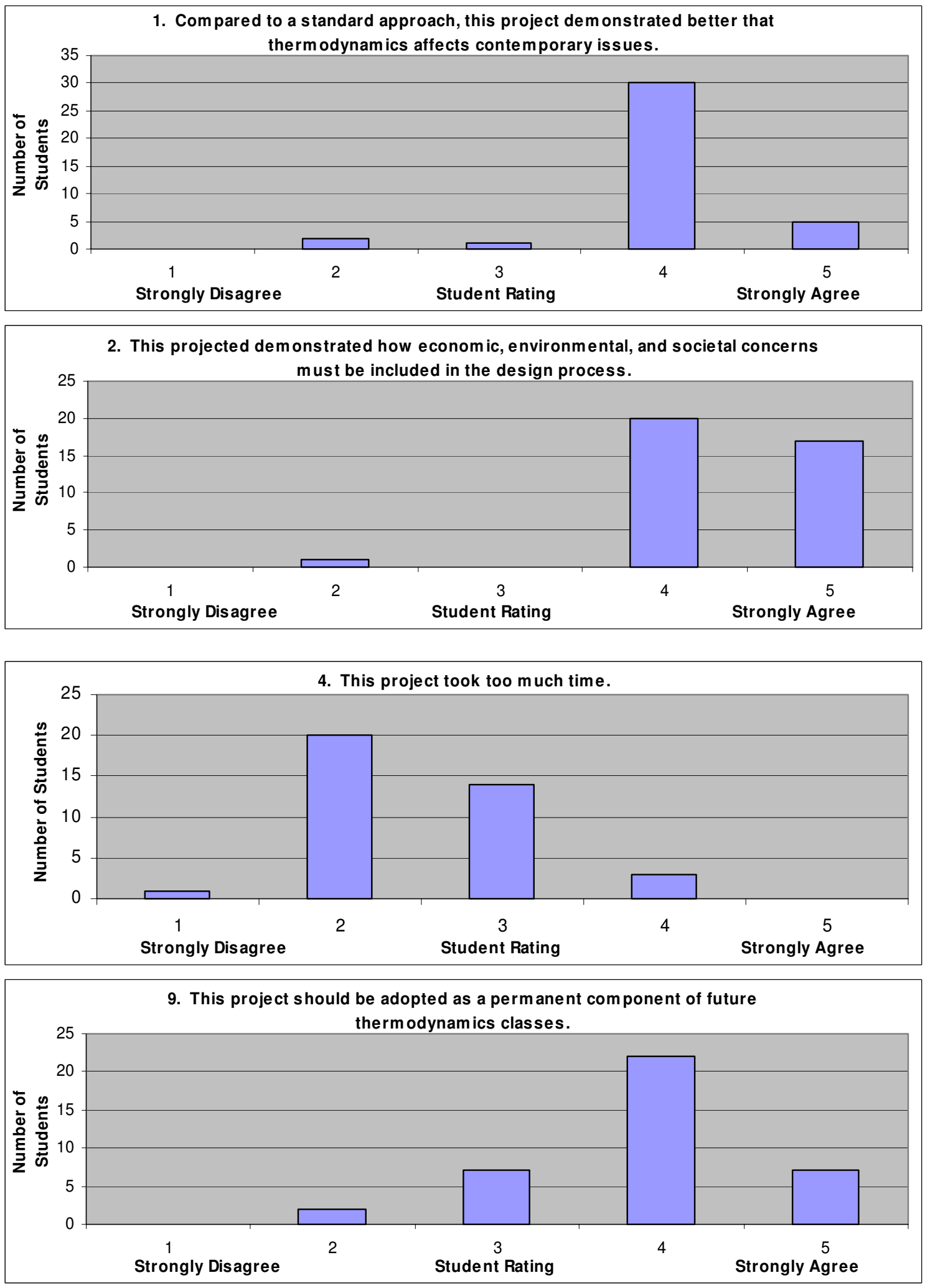